\title{
TITLE:
}

\section{Influence of calcium ions on subcritical crack growth in granite}

$\operatorname{AUTHOR}(\mathrm{S})$ :

Nara, Yoshitaka; Harui, Tomoki; Kashiwaya, Koki

\section{CITATION:}

Nara, Yoshitaka ...[et al]. Influence of calcium ions on subcritical crack growth in granite. International Journal of Rock Mechanics and Mining Sciences 2018, 102: 71-77

\section{ISSUE DATE:}

2018-02

URL:

http://hdl.handle.net/2433/230348

\section{RIGHT:}

(c) 2018. This manuscript version is made available under the CC-BY-NC-ND 4.0 license

http://creativecommons.org/licenses/by-nc-nd/4.0/; The full-text file will be made open to the public on 01 Februan 2020 in accordance with publisher's 'Terms and Conditions for Self-Archiving'.; This is not the published version. Please cite only the published version.; この論文は出版社版でありません。引用の際には出版社版をご磪認じ利用ください。 


\title{
Manuscript Details
}

\section{Manuscript number}

Title
IJRMMS_2017_117_R1

Influence of calcium ions on subcritical crack growth in granite

\section{Article type}

Technical note

\begin{abstract}
Granite rock masses are used for various geomechanical and engineering purposes such as the construction of underground repositories for radioactive waste. Investigating the fracturing in granite, especially time-dependent fracturing, is therefore crucial to consider the long-term integrity of granite rock mass surrounding structures.

Subcritical crack growth is one of the main causes of the time-dependent fracturing in rock materials. For the long-term integrity of the structures in a rock mass, it is essential to investigate subcritical crack growth in rock, which is influenced by the surrounding environmental conditions. Numerous cementitious materials are used to construct various structures such as underground repositories for radioactive waste, underground power plants, etc. In these cases, the calcium ion concentration in the ground water in a rock mass surrounding these structures is high. Therefore, investigations on the subcritical crack growth of rock in water with a high calcium ion concentration are necessary. In this study, subcritical crack growth in granite is measured in distilled water and a calcium hydroxide solution to investigate the influence of calcium ions on the time-dependent fracturing in rock. Oshima granite was used as a rock sample. The load-relaxation method of the double-torsion test was used to measure the crack velocity and the stress intensity factor. All measurements have been carried out under controlled temperature and relative humidity. It was shown that the crack velocity in a calcium hydroxide solution is lower than that in distilled water even though the $\mathrm{pH}$ was high. It was also found that precipitation of calcium compounds closes the crack, suggesting that precipitation decreases the crack velocity. Subcritical crack growth index of granite obtained in a calcium hydroxide solution was higher than that in distilled water, which brought about higher long-term strength and longer time-to-failure. It is concluded that a water environment with a high calcium ion concentration is suitable for the long-term integrity of granite rock mass.
\end{abstract}

\section{Keywords}

Corresponding Author

Order of Authors subcritical crack growth; granite; water; calcium ion; precipitation; double-torsion test

Yoshitaka Nara

Yoshitaka Nara, Tomoki Harui, Koki Kashiwaya

\section{Submission Files Included in this PDF}

\author{
File Name [File Type] \\ Cover_Letter-IJRM-r1.doc [Cover Letter]
}

Answer_to_reviewer.docx [Response to Reviewers]

Marked_Manuscript-SCG_Ca-IJRM-r1.docx [Revised Manuscript with Changes Marked]

Revised_Manuscript-SCG_Ca-IJRM-r1.docx [Manuscript File]

Figure1(DT_specimen)-submitted.jpg [Figure]

Figure2(DT-apparatus(PMMA-tank))-r1.jpg [Figure]

Figure3a(Photo_intact_specimen)-submitted.jpg [Figure]

Figure3b(Photo_precracked_specimen)-submitted.jpg [Figure]

Figure4(RLX_curves)_submitted.jpg [Figure]

Figure5(KV_curves_OG_Ca)-submitted.jpg [Figure]

Figure6a(crack_path_SEM)-submitted.jpg [Figure]

Figure6b(crack_path_mapping_Ca)-submitted.jpg [Figure]

Figure7a(LTS_OG_Ca_water)-submitted.jpg [Figure]

Figure7b(LTS_OG_Ca_water-exp)-submitted.jpg [Figure] 
Influence of calcium ions on subcritical crack growth in granite

Yoshitaka Nara $^{1}$, Tomoki Harui ${ }^{2}$, Koki Kashiwaya ${ }^{3}$

1. Department of Civil and Earth Resources Engineering, Graduate School of

Engineering, Kyoto University, Kyoto Daigaku Katsura, Nishikyo-ku, Kyoto 615 8540, Japan

2. Department of Management of Social Systems and Civil Engineering, Graduate School of Engineering, Tottori University, 4-101 Koyama-Minami, Tottori 680-8552, Japan

3. Department of Urban Management, Graduate School of Engineering, Kyoto University, Kyoto Daigaku Katsura, Nishikyo-ku, Kyoto 615-8540, Japan

*Corresponding author: Yoshitaka Nara

Address: Department of Civil and Earth Resources Engineering, Graduate School of Engineering, Kyoto University, Kyoto Daigaku Katsura, Nishikyo-ku, Kyoto 615-8540, Japan

E-mail: nara.yoshitaka.2n@kyoto-u.ac.jp

TEL: +81-75-383-3210 
Keywords: Subcritical crack growth; Granite; Water; Calcium ion; Precipitation; Double-torsion test 


\section{Introduction}

Granite rock masses are used for various geomechanical and engineering purposes such as the construction of caverns to store liquid natural gas or liquid petroleum gas, extraction of geothermal energy from hot dry rock, and underground repositories for radioactive waste. Investigating the fracturing in granite, especially time-dependent fracturing, is crucial to consider the long-term integrity of granite rock mass surrounding structures.

Subcritical crack growth is one of the main causes responsible for the time-dependent behaviors in rocks in the brittle regime $[1,2]$. SCG was initially attributed to stress corrosion, which is the chemical reaction between siloxane at the crack tip under tension and water [3, 4]. However, SCG is also influenced by the surrounding environment. Nara and Kaneko $[5,6]$ reported that the crack velocity in igneous rock in air increases when the partial pressure of water vapor is high. Nara et al. [7, 8] reported that the crack velocity in igneous rocks and sandstones in air increases as the temperature and/or relative humidity increases. The influence of water on SCG in glass, silicate minerals and rocks has been studied by various researchers. It is well-known that the crack velocity in glass in water is higher than that in water [9-12]. According to the results in Atkinson [13], Waza et al. [14], Meredith and Atkinson [15], Sano and Kudo [16], and Nara et al. [17, 18], the crack velocity in quartz and silicate rocks in water is much higher than that in air. Swanson $[19,20]$ reported that the addition of water on silicate rocks affected the deformation of rock and accelerated the crack velocity. The increases of the crack velocity in carbonate rocks in water have been reported by Henry et al. [21] for micrite and Nara et al. [22] for marble. Sano and Kudo [16] also showed that the $\mathrm{pH}$ influences the crack velocity of rock in water. Nara et al. [23] reported that the crack velocity in sandstone 
containing a large amount of clay minerals (illite and smectite) is influenced by the electrolyte concentration in water.

These previous studies of SCG in rock demonstrate SCG is influenced by the surrounding environmental conditions. In particular, the quality of water remarkably influences SCG of rock in water. Considering the construction of structures using a rock mass such as an underground repository of radioactive waste and underground power plant, numerous amounts of cementitious materials will be used. The calcium ion concentration in water in the surrounding rock mass should be high. Therefore, it is important to investigate the influence of calcium ions on SCG in rock to ensure the longterm stability of the rock mass.

In this study, SCG in distilled water and a calcium hydroxide $\left(\mathrm{Ca}(\mathrm{OH})_{2}\right)$ solution was investigated using granite as the rock sample to clarify the influence of calcium ions on SCG. Specifically, the difference of the crack velocity in distilled water and a calcium hydroxide solution was investigated using a fracture mechanics test.

\section{Rock sample}

The rock sample was Oshima granite from Ehime Prefecture, Japan. It is comprised of quartz (36\%), plagioclase (37\%), K-feldspar (22\%), biotite (4\%) and hornblende (less than 1\%) [24]. The mean grain size was about $1 \mathrm{~mm}$ [25]. Any clay minerals were not included $[24,25]$.

Several granites possess a preferred orientation of pre-existing microcracks [26-28]. According to the microscopic observation by Sano et al. [27], Oshima granite has two sets of preferred orientations of pre-existing microcracks. Most of the microcracks are distributed within the rift plane, and the secondary orientation of microcrack is distributed 
almost perpendicular to the rift plane, which is known as the grain plane. Additionally, Sano et al. [27] and Nara and Kaneko [6] concluded that Oshima granite has an orthorhombic elasticity due to the preferred orientation of the microcracks. For the sample block used in this study, the P-wave velocities measured in the direction normal to the rift plane, grain plane, and hardway plane (the third plane with the smallest distribution of microcracks) are 4.91, 4.61 and $4.51 \mathrm{~km} / \mathrm{s}$, respectively. We call these directions as axes-1, -2 , and -3 in the order of the P-wave velocity. Table 1 summarizes the orthorhombic elastic compliance of Oshima granite [6].

Sano and Kudo [16], Nara and Kaneko [6], and Nara et al. [29] reported that the crack velocity of Oshima granite has anisotropy. According to Nara and Kaneko [6], the crack velocity propagating parallel to the rift plane is 3 - 5 orders of magnitude higher than the velocity of a crack propagating parallel to the hardway plane. Nara [30] reported that the fracture toughness of Oshima granite is anisotropic and is the lowest when the crack propagated parallel to the rift plane. Therefore, it is necessary to consider the loading direction and specimen orientation which influence the crack propagation direction when preparing the specimens to measure SCG. We oriented our granite specimens so that the loading direction and the tensile direction are parallel to axis-3 and axis-1, respectively. This specimen is the same as "specimen $3 \cdot 1$ " in Sano and Kudo [16], Nara and Kudo [6], and Nara et al. [29].

\section{Methodology}

\subsection{Experimental method}

In this study, the load relaxation method of the double-torsion (DT-RLX) test was used to measure SCG. Fig. 1 schematically illustrates the specimen and loading configuration 
for the DT-RLX test. As summarized by Evans [31], Williams and Evans [32], and Sano [33], the stress intensity factor is independent of the crack length in the DT test. For this reason, various researchers have used the DT test to investigate SCG in rock [34].

In the RLX method, the displacement of the loading points must be kept constant during the experiment while the temporal decrease (load relaxation) due to the crack growth is measured. Considering the orthorhombic elasticity of Oshima granite $[6,16]$, the directions of the principal axes, the orientation of the specimen, and the loading direction on the specimen, it is appropriate to use the equations introduced by Sano and Kudo [16] to evaluate the stress intensity factor and crack velocity for Oshima granite. In this study, the loading direction and tensile direction are parallel to axis-1 and axis-3, respectively. Therefore, following the methodology by Sano and Kudo [16] and Nara and Kaneko [6], the stress intensity factor and the crack velocity are evaluated from following equations:

$$
\begin{gathered}
K_{\mathrm{I}}=\left(\frac{3 P^{2} w_{\mathrm{m}} s_{55}}{\left(2 d^{3} d_{\mathrm{n}}\left(2 s_{11}\left(\left(s_{33} s_{11}\right)^{1 / 2}+s_{31}+s_{55} / 2\right)\right)^{1 / 2}\right.}\right)^{1 / 2} \\
\frac{\mathrm{d} a}{\mathrm{~d} t}=-0.2 \times \frac{2 P_{i} \lambda_{i} d^{3}}{3 s_{55} w_{\mathrm{m}} P^{2}} \frac{\mathrm{d} P}{\mathrm{~d} t}
\end{gathered}
$$

where $K_{\mathrm{I}}$ is the stress intensity factor, $a$ is the crack length, and $\mathrm{d} a / \mathrm{d} t$ is the crack velocity. $P$ is the applied load, $w_{\mathrm{m}}$ is the moment arm (18 $\mathrm{mm}$ in this study), and $v$ is Poisson's ratio. $W$ is the width, while $d$ is the thickness of the specimen, and $d_{\mathrm{n}}$ is the reduced thickness of the specimen. $P_{\mathrm{i}}$ is the initial value of the applied load, $\lambda_{\mathrm{i}}$ is the compliance of the specimen at the initial crack length $a_{\mathrm{i}}$, and $\mathrm{d} P / \mathrm{d} t$ is the load relaxation rate. $s_{11}, s_{33}$, $s_{31}$ and $s_{55}$ are the elastic compliance of the sample.

Because these are approximate solutions based on a thin-plate assumption, the size of 
the specimen must satisfy the following condition [35-37]:

$$
12 d \leq W \leq L / 2
$$

where $L$ is the specimen length. According to the previous studies by Ciccoti and coworkers [38-41], thicker specimens $(W: d=8: 1)$ can be used for DT-RLX test.

Trantina [42] reported that the stress intensity factor is independent of the crack length over the following range:

$$
0.55 W<a<L-0.65 W
$$

Considering these restrictions, the specimen size in this study was set to a width $W=$ $45[\mathrm{~mm}]$, thickness $d=3[\mathrm{~mm}]$, reduced thickness $d_{\mathrm{n}}=2[\mathrm{~mm}]$, and length $L=140[\mathrm{~mm}]$.

It is necessary to make a guide groove in a DT specimen to control the crack path. It has been suggested that the shape of the guide groove should be rectangular for rock because the crack often propagates away from the guide groove in cases with semicircular or triangular guide grooves [5]. Nara [43] reported that a crack often propagates away from the guide groove when the width of the guide groove is smaller than the grain size in granite. Considering previous studies, the width of the guide groove was set to 1 $\mathrm{mm}$ because the grain size of Oshima granite is around $1 \mathrm{~mm}$. In addition, a $20 \mathrm{~mm}$ long notch was cut in the central part of the DT specimen from one end in order to help crack propagate in the central part of the specimen. This is called the "initial notch". In the DT test, the load was applied near the initial notch.

\subsection{Experimental apparatus}

Fig. 2 shows the experimental apparatus for the DT-RLX test. In this apparatus, the load was applied to the specimen from the loading cylinder placed above the specimen. A stepping motor controlled the loading cylinder. All measurements were conducted at a 
constant temperature by placing the apparatus in a thermostat chamber, in which the change of the temperature was less than $0.1 \mathrm{~K}$ during a measurement of the DT-RLX test. Since the apparatus is constructed using a stainless steel, the rigidity is high enough to avoid the load-relaxation from the apparatus [37]. Therefore, we can obtain the loadrelaxation only due to the crack growth in rock using the apparatus in this study.

In addition, all measurements were conducted in aqueous environments over several days. Distilled water or a calcium hydroxide solution was supplied to the apparatus slowly using a droplet bag placed beside the thermostat chamber to avoid evaporation.

\subsection{Experimental procedure}

At first, a short crack was introduced in the specimen by applying the load slowly using a "pre-cracking" procedure. Figs. $3 \mathrm{a}$ and $3 \mathrm{~b}$ show photos of the specimen surface of around the initial notch for an intact specimen and pre-cracked specimen, respectively. Pre-cracking was done until the length of the crack (initial notch and induced crack) reached $25 \mathrm{~mm}$, which is the lower limit of the condition shown in Eq. (4). Then the specimen was placed in distilled water or a calcium hydroxide solution with a calcium ion concentration of $1150 \mathrm{mg} / \mathrm{l}$ in a desiccator, and saturated using a vacuum pump. The specimen was submersed in water or a calcium hydroxide $\left(\mathrm{Ca}(\mathrm{OH})_{2}\right)$ solution for $1-2$ weeks. The saturated specimen was then put on the apparatus for the DT test with water or $\mathrm{Ca}(\mathrm{OH})_{2}$ solution, and kept at a constant temperature for more than 20 hours. Afterwards the DT-RLX test was conducted.

For the results of DT-RLX method, the scatterings of the experimental results (the evaluations of the crack velocity, the stress intensity factor, and the subcritical crack growth index) have been reported when experiments were conducted several times on a 
single specimen of heterogeneous materials [20, 33, 44-46]. Sano [33] suggested that this scattering was caused by locking at the crack faces, because this kind of the scattering was not observed on the glass. Nara and Kaneko $[5,6]$ conducted the measurements of DT-RLX method with rocks with considering the loading condition ensuring that a wide crack opened in the DT specimen. In addition, an experimental run using the RLX method on a single specimen should be performed only once to avoid the repeated crack opening and closing. Following this procedure, Nara et al. [47] showed the environmental dependence of the subcritical crack growth index of igneous rocks (granite and andesite) using DT-RLX method. The procedure in this study follows those by Nara and Kaneko $[5,6]$ and Nara et al. [47], in which the loading points were rapidly moved $0.24 \mathrm{~mm}$ after the $14-15 \mathrm{~N}$ preload was applied for granite specimens.

\section{Results}

Fig. 4 shows the load relaxation curves obtained in water environments (distilled water and a $\mathrm{Ca}(\mathrm{OH})_{2}$ solution). For comparison, the load relaxation curve obtained in air is also shown. The applied load on the specimen in the $\mathrm{Ca}(\mathrm{OH})_{2}$ solution is higher than that on the specimen in distilled water, suggesting that a higher stress intensity factor is necessary for crack propagation in granite in water with a higher calcium ion concentration. In addition, the applied load on the specimens in water environments is higher than those in air. This tendency agrees well with previous studies, for example, by Waza et al. [14], Sano and Kudo [16], and Nara et al. [17].

The data in Fig. 4 and Eqs. (1) and (2) can be used to calculate the crack velocity and the stress intensity factor. Fig. 5 shows the relationships between the crack velocity and the stress intensity factor in granite in distilled water and $\mathrm{Ca}(\mathrm{OH})_{2}$ solution. For 
comparison, the relationship obtained in air is also shown. It is obvious that the crack velocities in aqueous environments $\left(\mathrm{Ca}(\mathrm{OH})_{2}\right.$ solution and distilled water) are much higher than that in air. In the case for the measurement in air, the temperature is slightly higher (about $12 \mathrm{~K}$ ). If the temperature decreases, it is known that the stress intensity factor increase and the crack velocity decreases for rocks [7, 47]. According to Nara et al. [47], $45 \mathrm{~K}$ temperature drop brought about the decrease of the crack velocity in Oshima granite by 2 - 3 orders of magnitude. It is thus considered that the decrease of the temperature by $12 \mathrm{~K}$ brings about slight decrease on the crack velocity in Oshima granite. Therefore, even if the temperature for the measurement in air decreases by $12 \mathrm{~K}$, the crack velocity is still much lower than those in aqueous environments, which is the same tendency shown in Fig. 5.

It is obvious that the crack velocity in the $\mathrm{Ca}(\mathrm{OH})_{2}$ solution is higher than that in distilled water, indicating that the calcium ion concentration can affect the crack velocity for granite in water. Additionally, the crack velocity in water environments is much higher than that in air. This tendency agrees well with previous studies [14, 16, 17, 48-51].

For $\mathrm{SCG}$, the crack velocity $\mathrm{d} a / \mathrm{d} t$ is empirically related to the stress intensity factor $\mathrm{d} a / \mathrm{d} t$ as $[52,53]:$

$$
\begin{gathered}
\frac{\mathrm{d} a}{\mathrm{~d} t}=A K_{\mathrm{I}}^{n} \\
\frac{\mathrm{d} a}{\mathrm{~d} t}=v_{0} \exp \left(\frac{-E^{t}+b K_{\mathrm{I}}}{R T}\right)
\end{gathered}
$$

where $E^{\ddagger}$ is the stress-free activation energy, $R$ is the gas constant, and $T$ is the absolute temperature. The other variables are experimentally determined constants. $n$ is the subcritical crack growth index. The relationships expressed by Eq. (5) and Eq. (6) are called the power law [52] and the exponential law [53], respectively. We used these 
equations to summarize the experimental results. In particular, we used the following equation of the exponential law:

$$
\left.\begin{array}{l}
\ln \left(\frac{\mathrm{d} a}{\mathrm{~d} t}\right)=\alpha+\frac{b}{R T} K_{\mathrm{I}} \\
\because \alpha=\ln v_{0}-\frac{E^{\ddagger}}{R T}
\end{array}\right\}
$$

Tables 2 and 3 summarize the results of the SCG measurement for Oshima granite in distilled water and a $\mathrm{Ca}(\mathrm{OH})_{2}$ solution as well as the result in air. Tables 2 and 3 indicate the results obtained using the power law and the exponential law, respectively. The stress intensity factor for $\mathrm{d} a / \mathrm{d} t=10^{-6}[\mathrm{~m} / \mathrm{s}], K_{\mathrm{I}}\left(10^{-6}\right)$, is listed in this table to quantitatively compare its value because the range in the crack velocity is $10^{-2}-10^{-10}$ $\mathrm{m} / \mathrm{s}$. The values of the crack velocity at $K_{\mathrm{I}}=1.6\left[\mathrm{MN} / \mathrm{m}^{3 / 2}\right], \mathrm{d} a / \mathrm{d} t(1.6)$, are listed in

Table 1 . The crack velocity is lower while the stress intensity factor is higher in a $\mathrm{Ca}(\mathrm{OH})_{2}$ solution than those in distilled water, suggesting that SCG is inhibited in water with a high calcium ion concentration. In addition, it is recognized that the values of $n$ and $b$ (slope for the relationship between the crack velocity and the stress intensity factor) are higher for the $\mathrm{Ca}(\mathrm{OH})_{2}$ solution than that in distilled water.

\section{Discussion}

The crack velocity for SCG in water with a high calcium ion concentration is lower than that in distilled water. Thus, it is essential to consider the influence of water quality on the crack velocity for SCG. It has been considered that high $\mathrm{pH}$ increase the crack velocity in silicate materials. Atkinson and Meredith [54] measured SCG in synthetic quartz in deionized water, hydrochloric acid $(\mathrm{HCl})$ and sodium hydroxide $(\mathrm{NaOH})$, and reported that the crack velocity in synthetic quartz increased when SCG occurred in 
$\mathrm{NaOH}$ solution. As mentioned before, Sano and Kudo [16] reported that the crack velocity in silicate rock in water increases when the $\mathrm{pH}$ of water is higher. Especially, they measured SCG in granite and basalt in sulfuric acid $\left(\mathrm{H}_{2} \mathrm{SO}_{4}\right)$, deionized water, and $\mathrm{NaOH}$ solution, and reported that the crack velocity in $\mathrm{NaOH}$ solution was the highest. In contrast, we measured SCG in granite in water and $\mathrm{Ca}(\mathrm{OH})_{2}$ solution, and the crack velocity in this study decreases although the $\mathrm{pH}$ is higher (Tables 2 and 3). It is suggested that the influence of $\mathrm{Ca}(\mathrm{OH})_{2}$ on the crack velocity in silicate materials is different from $\mathrm{NaOH}$ even though they are alkali. Therefore, it is necessary to consider different reasons for the decrease in the crack velocity other than the $\mathrm{pH}$.

If it is possible to observe actually propagating crack tip, the detailed mechanism of the decrease of the crack velocity in $\mathrm{Ca}(\mathrm{OH})_{2}$ can be revealed. Since it is impossible to observe the actually propagating crack tip in the apparatus in this study, we decided to observe the crack path, which was the crack tip in the past.

We tried to observe the crack path using the scanning electron microscope (SEM) with the energy dispersive X-ray spectroscopy (EDS) by preparing a polished thin section of the rock specimen used in the $\mathrm{Ca}(\mathrm{OH})_{2}$ solution measurements. When we prepared a polished thin section, cyanoacrylate resin was put in the rock specimen to protect the crack path $[55,56]$. Fig. 6 shows the images obtained by SEM and the elemental mapping of calcium. The precipitation of calcium can be recognized in the crack path. Similar precipitations were not observed in the specimen in the distilled water measurements. These observations indicate that the precipitation of calcium compounds occurred around the crack tip in the past, which could yields a lower crack velocity in the $\mathrm{Ca}(\mathrm{OH})_{2}$ solution than that in distilled water.

The values of $n$ (subcritical crack growth index, see Eq. (4)) and $b$ (see Eq. (5)) in 
$\mathrm{Ca}(\mathrm{OH})_{2}$ are higher than those in distilled water. According to Nara et al. [47], the subcritical crack growth index in rock tends to be higher in an environment where SCG is depressed. Since SCG in water with a higher calcium ion concentration seems to be depressed, the higher $n$ and $b$ in $\mathrm{Ca}(\mathrm{OH})_{2}$ are considered to be reasonable.

It is known that the values of $n$ and $b$ influence the long-term strength of materials. For the evaluation of the long-term strength, we considered a situation where an infinite plate containing a single crack with the length of $2 a$ is subjected to a uniform tensile stress $\sigma$. In this case, the stress intensity factor is expressed as follows:

$$
K_{\mathrm{I}}=\sigma(\pi a)^{1 / 2} .
$$

If we use the power law of SCG expressed with Eq. (5), the following equation can be obtained:

$$
\frac{\mathrm{d} a}{\mathrm{~d} t}=\pi^{n / 2} A \sigma^{n} a^{n / 2} .
$$

From Eq. (8), the following equation can be obtained:

$$
\int a^{-n / 2} \mathrm{~d} a=\int \pi^{n / 2} A \sigma^{n} \mathrm{~d} t
$$

The general solution of the above equation is expressed as follows:

$$
\frac{1}{1-n / 2} a^{1-n / 2}=\pi^{n / 2} A \sigma^{n} t+c
$$

where $c$ is a constant of integration. Assuming that $a=a_{0}$ when $t=0$, the constant $c$ can be determined as follows:

$$
\frac{2}{2-n} a_{0}^{(2-n) / 2}=c \text {. }
$$

Substituting Eq. (11) into Eq. (10), the following equation can be obtained:

$$
a^{(2-n) / 2}=\frac{2-n}{2} \pi^{n / 2} A \sigma^{n} t+a_{0}^{(2-n) / 2} .
$$

From this equation, the following equation can be obtained: 


$$
t=\frac{2}{(n-2) \pi^{n / 2} A} \frac{a_{0}^{(2-n) / 2}}{\sigma^{n}}\left\{1-\left(\frac{a}{a_{0}}\right)^{(2-n) / 2}\right\} .
$$

Even though the crack propagates statically, the manner of the crack propagation will change from static to dynamic as time goes by. In addition, the crack length will diverge. Assuming that the time when the crack length diverges is called as "time-to-failure", this can be expressed as follows:

$$
t_{\mathrm{f}}=\frac{2}{(n-2) \pi^{n / 2} A} \frac{a_{0}^{(2-n) / 2}}{\sigma^{n}} .
$$

where $t_{\mathrm{f}}$ is time-to-failure. Considering the situation that a material reaches failure in $x$ years under a constant stress, this stress is defined as "long-term strength", $S_{\mathrm{t}}(x)$. Because the time-to-failure is $x$ years $\left(3.15 \times 10^{7} x\right.$ seconds $)$ under this stress, the following equation can be obtained from Eq. (14):

$$
\left(S_{\mathrm{t}}(x)\right)^{n}=\frac{1}{3.15 \times 10^{7} x} \frac{2}{(n-2) \pi^{n / 2} A} a_{0}^{(2-n) / 2} .
$$

Assuming that the tensile strength and the fracture toughness of a material are $S_{\mathrm{t}}$ and $K_{\mathrm{IC}}$, respectively, when the crack length is $a_{0}$, the relationship between $S_{\mathrm{t}}$ and $K_{\mathrm{IC}}$ can be expressed as follows:

$$
K_{\mathrm{IC}}=S_{\mathrm{t}}\left(\pi a_{0}\right)^{1 / 2}
$$

From Eqs. (15) and (16), we can obtain the following equation:

$$
S_{\mathrm{t}}(x)=\left\{\frac{1}{3.15 \times 10^{7} x} \frac{2}{(n-2) \pi A}\right\}^{1 / n}\left(\frac{K_{\mathrm{IC}}}{S_{\mathrm{t}}}\right)^{(2-n) / n} .
$$

By using this equation, we can estimate the long-term strength based on the power law of SCG [57].

Next, we explain how to estimate long-term strength and time-to-failure of a material 
using the exponential law of subcritical crack growth expressed with Eq. (6). If the $K_{\mathrm{I}^{-}}$ $\mathrm{d} a / \mathrm{d} t$ relation is expressed with Eq. (6), substituting Eq. (7) into Eq. (6), the following equation can be obtained:

$$
\left.\begin{array}{l}
\frac{\mathrm{d} a}{\mathrm{~d} t}=v_{1} \exp \left(b^{\prime} \sqrt{a}\right) \\
\because v_{1}=v_{0} \exp \left(\frac{-E^{\ddagger}}{R T}\right)=\exp \alpha, b^{\prime}=\frac{b}{R T} \sigma \sqrt{\pi}
\end{array}\right\}
$$

From this equation, the following equation can be obtained:

$$
\int_{a_{0}}^{a} \exp \left(-b^{\prime} \sqrt{a}\right) \mathrm{d} a=\int_{0}^{t} v_{1} \mathrm{~d} t
$$

If we assume that $a^{1 / 2}=\xi$, the left side of Eq. (19) can be arranged as follows:

$$
\begin{aligned}
\int_{a_{0}}^{a} \exp \left(-b^{\prime} \sqrt{a}\right) \mathrm{d} a & =2 \int_{\sqrt{a_{0}}}^{\sqrt{a}} \xi \exp \left(-b^{\prime} \xi\right) \mathrm{d} \xi \\
& =\frac{2}{\beta^{\prime^{2}}}\left(b^{\prime} \sqrt{a_{0}}+1\right) \exp \left(-b^{\prime} \sqrt{a_{0}}\right)-\frac{2}{b^{\prime 2}}\left(b^{\prime} \sqrt{a}+1\right) \exp \left(-b^{\prime} \sqrt{a}\right)
\end{aligned}
$$

From Eqs. (19) and (20), we can obtain the following equation:

$$
\frac{2}{b^{\prime 2}}\left(b \sqrt{a_{0}}+1\right) \exp \left(-b^{\prime} \sqrt{a_{0}}\right)-\frac{2}{b^{\prime 2}}\left(b^{\prime} \sqrt{a}+1\right) \exp \left(-b^{\prime} \sqrt{a}\right)=v_{1} t
$$

In Eq. (21), the first term on the left hand side is a constant. The second term converges on 0 with increasing $a$. Therefore, the time $t$ converges on a constant value with increasing crack length $a$. In this case, $a$ increases with elapsed time, and then diverges at a given $t$. For convenience of calculation, a solution about $t$ is desirable. Based on this consideration, the following equation is obtained from Eq. (21):

$$
t=\frac{2}{v_{1} b^{\prime 2}}\left(b^{\prime} \sqrt{a_{0}}+1\right) \exp \left(-b^{\prime} \sqrt{a_{0}}\left[1-\frac{\left(b^{\prime} \sqrt{a}+1\right)}{\left(b^{\prime} \sqrt{a_{0}}+1\right)} \exp \left\{-b^{\prime}\left(\sqrt{a}-\sqrt{a_{0}}\right)\right\}\right]\right.
$$

The time-to-failure $t_{\mathrm{f}}$ is obtained by the following equation assuming that $a$ diverges in 
Eq. (22):

$$
t_{\mathrm{f}}=\frac{2}{v_{1} b^{\prime 2}}\left(b^{\prime} \sqrt{a_{0}}+1\right) \exp \left(-b^{\prime} \sqrt{a_{0}}\right)
$$

This equation can be rewritten as follows:

$$
t_{\mathrm{f}}=\frac{2}{(\exp \alpha) \pi(b / R T)^{2} \sigma^{2}}\left(\frac{b}{R T} \sigma \sqrt{\pi a_{0}}+1\right) \exp \left(-\frac{b}{R T} \sigma \sqrt{\pi a_{0}}\right)
$$

Assuming that the tensile strength and the fracture toughness of a material are $S_{\mathrm{t}}$ and $K_{\mathrm{IC}}$, respectively, when the crack length is $a_{0}$, the relation between $S_{\mathrm{t}}$ and $K_{\mathrm{IC}}$ can be expressed as follows:

$$
K_{\mathrm{IC}}=S_{\mathrm{t}}\left(\pi a_{0}\right)^{1 / 2}
$$

Since the time-to-failure is $x$ years $\left(3.15 \times 10^{7} x\right.$ seconds $)$ under this stress, the following equation can be obtained from Eq. (24):

$$
3.15 \times 10^{7} x=\frac{2}{(\exp \alpha) \pi(b / R T)^{2}\left(S_{\mathrm{t}}(x)\right)^{2}}\left(\frac{b}{R T} S_{\mathrm{t}}(x) \frac{K_{\mathrm{IC}}}{S_{\mathrm{t}}}+1\right) \exp \left(-\frac{b}{R T} S_{\mathrm{t}}(x) \frac{K_{\mathrm{IC}}}{S_{\mathrm{t}}}\right)
$$

By using this equation, we can estimate the long-term strength and time-to-failure of a material based on the exponential law of SCG [47].

Eqs. (17) and (25) indicate the estimation of the long-term strength based on the power law [52] and the exponential law [53], respectively. In Fig. 7, the relations between the time-to-failure and long-term strength of Oshima granite in distilled water and in $\mathrm{Ca}(\mathrm{OH})_{2}$ solution are shown. Figs. 7a and $7 \mathrm{~b}$ show the relation estimated based on the power law (Eq. (7)) and the exponential law (Eq. (8)), respectively. For the calculation of the longterm strength, we set the value of $K_{\mathrm{IC}}$ and $S_{\mathrm{t}}$ as $2.58\left[\mathrm{MN} / \mathrm{m}^{3 / 2}\right]$ and $7.85[\mathrm{MPa}]$, respectively, according to Nara [30]. It is recognized that the long-term strength is higher and the time-to-failure is longer for the rock in $\mathrm{Ca}(\mathrm{OH})_{2}$ solution. Therefore, an aqueous environment with a high calcium ion concentration is suitable for the long-term stability 
of a rock mass.

\section{Conclusions}

In this study, $\mathrm{SCG}$ in distilled water and a $\mathrm{Ca}(\mathrm{OH})_{2}$ solution was investigated to clarify the influence of calcium ions on SCG with an emphasis on the difference between the crack velocity in distilled water and that in a $\mathrm{Ca}(\mathrm{OH})_{2}$ solution. The crack velocity in the $\mathrm{Ca}(\mathrm{OH})_{2}$ solution is lower than that in distilled water. The precipitation of $\mathrm{CaCO}_{3}$ induces crack closures of the crack path of the granite in the $\mathrm{Ca}(\mathrm{OH})_{2}$ solution. The precipitation of calcium compound on the crack likely decreases the crack velocity for the rock sample in the $\mathrm{Ca}(\mathrm{OH})_{2}$ solution. Additionally, the value of the subcritical crack index of rock in $\mathrm{Ca}(\mathrm{OH})_{2}$ is higher than that in distilled water. It is concluded that the aqueous environment with a higher calcium ion concentration is suitable to ensure the long-term stability of a rock mass. 


\section{Acknowledgement}

This work was supported in part by a grant from the Ministry of Economy, Trade and Industry (METI). 


\section{References}

[1] Atkinson BK. Subcritical crack growth in geological materials. J Geophys Res $1984 ; 89: 4077-4114$

[2] Atkinson BK, Meredith PG. The theory of subcritical crack growth with applications to minerals and rocks. In Atkinson BK ed. Fracture Mechanics of Rock. London: Academic Press; 1987:111-166.

[3] Anderson OL, Grew PC. Stress corrosion theory of crack propagation with applications to geophysics. Rev Geophys Space Phys 1997;15:77-104.

[4] Michalske TA, Freiman SW. A molecular interpretation of stress corrosion in silica. Nature 1982;295:511-512.

[5] Nara Y, Kaneko K. Study of subcritical crack growth in andesite using the Double Torsion test. Int J Rock Mech Min Sci 2005;42:521-530.

[6] Nara Y, Kaneko K. Sub-critical crack growth in anisotropic rock. Int J Rock Mech Min Sci 2006;43:437-453.

[7] Nara Y, Hiroyoshi N, Yoneda T, Kaneko K. Effect of temperature and relative humidity on subcritical crack growth in igneous rock. Int J Rock Mech Min Sci 2010;47:640-646.

[8] Nara Y, Morimoto K, Yoneda T, Hiroyoshi N, Kaneko K. Effects of humidity and temperature on subcritical crack growth in sandstone. Int $\mathrm{J}$ Solids Struct 2011;48:1130-1140.

[9] Hillig WB, Charles RJ. Surfaces, stress-dependent surfaces reactions, and strength. In High-strength materials, John Wiley \& Sons, Inc., New York, pp.682-705.

[10] Wiederhorn SM. Influence of water vapor on crack propagation in soda-lime glass. 
J Am Ceram Soc 1967:50:407-414.

[11] Evans AG. A simple method for evaluating slow crack growth in brittle materials. Int J Fract 1973:9:267-275.

[12] Adams R, McMillan PW. Static fatigue in glass. J Mater Sci 1977:12:643-657.

[13] Atkinson BK. A fracture mechanics study of subcritical tensile cracking of quartz in wet environments. Pure Appl Geophys 1979:117:1011-1024.

[14] Waza T, Kurita K, Mizutani H. The effect of water on the subcritical crack growth in silicate rocks. Tectonophysics 1980;67:25-34.

[15] Meredith PG, Atkinson BK. Stress corrosion and acoustic emission during tensile crack propagation in Whin Sill dolerite and other basic rocks. Geophys J Astr Soc 1983:75:1-21.

[16] Sano O, Kudo Y. Relation of fracture resistance to fabric for granitic rocks. Pure Appl. Geophys 1992;138:657-677.

[17] Nara Y, Takada M, Igarashi T, Hiroyoshi N, Kaneko K. Subcritical crack growth in rocks in an aqueous environment. Explor Geophys 2009;40:163-171.

[18] Nara Y, Tanaka M, Harui T. Evaluating long-term strength of rock under changing environments from air to water. Eng Fract Mech 2017:178:201-211.

[19] Swanson PL. Subcritical crack propagation in Westerly granite: an investigation into the double-torsion method. Int J Rock Mech Min Sci \& Geomech Abstr 1981:18:445-449.

[20] Swanson PL. Subcritical crack growth and other time- and environment-dependent behavior in crustal rocks. J Geophys Res 1984:89:4137-4152.

[21] Henry JP, Paquet J, Tancrez JP. Experimental study of crack propagation in calcite rocks. Int J Rock Mech Min Sci \& Geomech Abstr 1977:14:85-91. 
[22] Nara Y, Kashiwaya K, Nishida Y, Ii T. Influence of surrounding environment on subcritical crack growth in marble. Tectonophysics 2017:706-707:116-128.

[23] Nara Y, Nakabayashi R, Maruyama M, Hiroyoshi N, Yoneda T, Kaneko K. Influences of electrolyte concentration on subcritical crack growth in sandstone in water. Eng Geol 2014;179:41-49.

[24] Sano O, Ito I, Terada M. Influence of strain rate on dilatancy and strength of Oshima granite under uniaxial compression. J Geophys Res 1981;86:9299-9311.

[25] Sano O. A note on the sources of acoustic emissions associated with subcritical crack growth. Int J Rock Mech Min Sci Geomech Abstr 1981;18:259-263.

[26] Dale TN. The commercial granite of New England. Bull US Geol Surv 1923;738:22103.

[27] Sano O, Kudo Y, Mizuta Y. Experimental determination of elastic constants of Oshima granite, Barre granite, and Chelmsford granite. J Geophys Res 1992;97:3367-3379.

[28] Nara Y, Kato H, Yoneda T, Kaneko K. Determination of three-dimensional microcrack distribution and principal axes for granite using a polyhedral specimen. Int J Rock Mech Min Sci 2011;48:316-335.

[29] Nara Y, Koike K, Yoneda T, Kaneko K. Relation between subcritical crack growth behavior and crack paths in granite. Int J Rock Mech Min Sci 2006;43:1256-1261.

[30] Nara Y. Effect of anisotropy on the long-term strength of granite. Rock Mech Rock Eng 2015;48:959-969.

[31] Evans AG. A method for evaluating the time-dependent failure characteristics of brittle materials - and its application to polycrystalline alumina. J Mater Sci 1972;7:137-1146. 
[32] Williams DP, Evans AG. A simple method for studying slow crack growth. J Test Eval 1973;1:264-270.

[33] Sano O. A revision of the double-torsion technique for brittle materials. J Mater Sci $1988 ; 23: 2505-2511$

[34] Atkinson BK, Meredith PG. Experimental fracture mechanics data for rocks and minerals. In Atkinson BK ed. Fracture Mechanics of Rock. London: Academic Press; 1987:477-525.

[35] Evans AG, Linzer M, Russell LR. Acoustic emission and crack propagation in polycrystalline alumina. Mater Sci Eng 1974;15:253-261.

[36] Atkinson BK. Fracture toughness of Tennessee sandstone and Carrara marble using the double torsion testing method. Int J Rock Mech Min Sci Geomech Abstr 1979; $16: 46-53$.

[37] Pletka BJ, Fuller Jr ER, Koepke BG. An evaluation of double-torsion testing Experimental. ASTM STP 678; 1979. p. 19-37.

[38] Ciccotti M. Realistic finite-element method for double-torsion loading configuration. J Am Ceram Soc 2000;83:2737-2744.

[39] Ciccotti M, Gonzato G, Mulargia F. The double torsion loading configuration for fracture propagation: an improved methodology for the load-relaxation at constant displacement. Int J Rock Mech Min Sci 2000;37:1103-1113.

[40] Ciccotti M, Negri N, Sassi L, Gonzato G, Mulargia F. Elastic and fracture parameters of Etna, Stromboli, and Vulcano lava rocks. J Volcanol Geother Res 2000;98:209217.

[41] Ciccotti M, Negri N, Gonzato G, Mulargia F. Practical application of an improved methodology for the double torsion load relaxation method. Int J Rock Mech Min 
Sci 2000;38:569-576.

[42] Trantina GG. Stress analysis of the double-torsion specimen. J Am Ceram Soc $1977 ; 60: 338-341$.

[43] Nara Y. Study of subcritical crack growth in rock. Ph.D. Thesis, Hokkaido University, 2004 (in Japanese).

[44] Pletka BJ, Wiederhorn SM. Subcritical crack growth in glass-ceramics. In Bradt RC, Hasselman DPH, Lange FF eds. Fracture Mechanics of Ceramics 4. New York: Prenum Press; 1978:745-759.

[45] Ferver MK, Brown SD. Subcritical crack growth in dense alumina exposed to physiological media. J Am Ceram Soc 1980:63:424-429.

[46] Swanson PL. Subcritical fracture propagation in rocks: an examination using the methods of fracture mechanics and non-destructive testing. Ph.D.Thesis. University of Colorado, Boulder. 1985.

[47] Nara Y, Yamanaka H, Oe Y, Kaneko K. Influence of temperature and water on subcritical crack growth parameters and long-term strength for igneous rocks. Geophys J Int 2013;193:47-60.

[48] Hadizadeh J, Law RD. Water-weakening of sandstone and quartzite deformed at various stress and strain rates. Int J Rock Mech Min Sci 1991;28:431-439.

[49] Baud P, Zhu W, Wong T-F. Failure mode and weakening effect of water on sandstone. J Geophys Res 2000;105:16371-16389.

[50] Heap MJ, Baud P, Meredith PG, Vinciguerra S, Bell AF, Main IG. Brittle creep in basalt and its application to time-dependent volcano deformation. Earth Planet Sci Lett 2011;307:71-82.

[51] Brantut N, Heap MJ, Meredith PG, Baud P. Time-dependent cracking and brittle 
creep in crustal rocks: A review. J Struct Geol 2013;52:17-43.

[52] Charles RJ. Static fatigue of glass II. J Appl Phys 1958;29:1554-1560.

[53] Wiederhorn SM, Bolz LH. Stress Corrosion and Static Fatigue of Glass. J Am Ceram Soc 1970;53:543-548.

[54] Atkinson BK, Meredith PG. Stress corrosion cracking of quartz: a note on the influence of chemical environment. Tectonophysics 1981:77:T1-T11.

[55] Nishiyama T, Kusuda H. Identification of pore spaces and microcracks using fluorescent resins. Int J Rock Mech Min Sci Geomech Abstr 1994;31:369-75.

[56] Chen Y, Nishiyama T, Kusuda H, Kita H, Sato T. Correlation between microcrack distribution patterns and granitic rock splitting planes. Int J Rock Mech Min Sci 1999;36:535-541.

[57] Nara Y, Takada M, Mori D, Owada H, Yoneda T, Kaneko K. Subcritical crack growth and long-term strength in rock and cementitious material. Int J Fract 2010;164:57-71. 


\section{Figure captions}

Fig. 1. Schematic illustration of the specimen and loading configuration in the doubletorsion test.

Fig. 2. Schematic illustration of the apparatus in the double-torsion test.

Fig. 3. Photo of (a) the intact specimen and (b) pre-cracked specimen surface around initial notch. Width and height of images are 2.3 and $2.0 \mathrm{~mm}$, respectively.

Fig. 4. Load relaxation curves for Oshima granite.

Fig. 5. Relationships between the crack velocity and the stress intensity factor for Oshima granite.

Fig. 6. Image of precipitation in the crack path in granite. (a): SEM photomicrograph, (b) Elemental mapping of calcium by EDS

Fig. 7. Relationships between long-term strength and time-to-failure for Oshima granite in distilled water and $\mathrm{Ca}(\mathrm{OH})_{2}$ solution estimated based on (a) power law and (b) exponential law. 


\section{Table captions}

Table 1. Elastic compliance of the Oshima granite (after Nara and Kaneko [6]).

Table 2. Results of subcritical crack growth measurements summarized by the power law.

Table 3. Results of subcritical crack growth measurements summarized by the exponential law. 
Table 1. Elastic compliance of the Oshima granite (after Nara and Kaneko [6]).

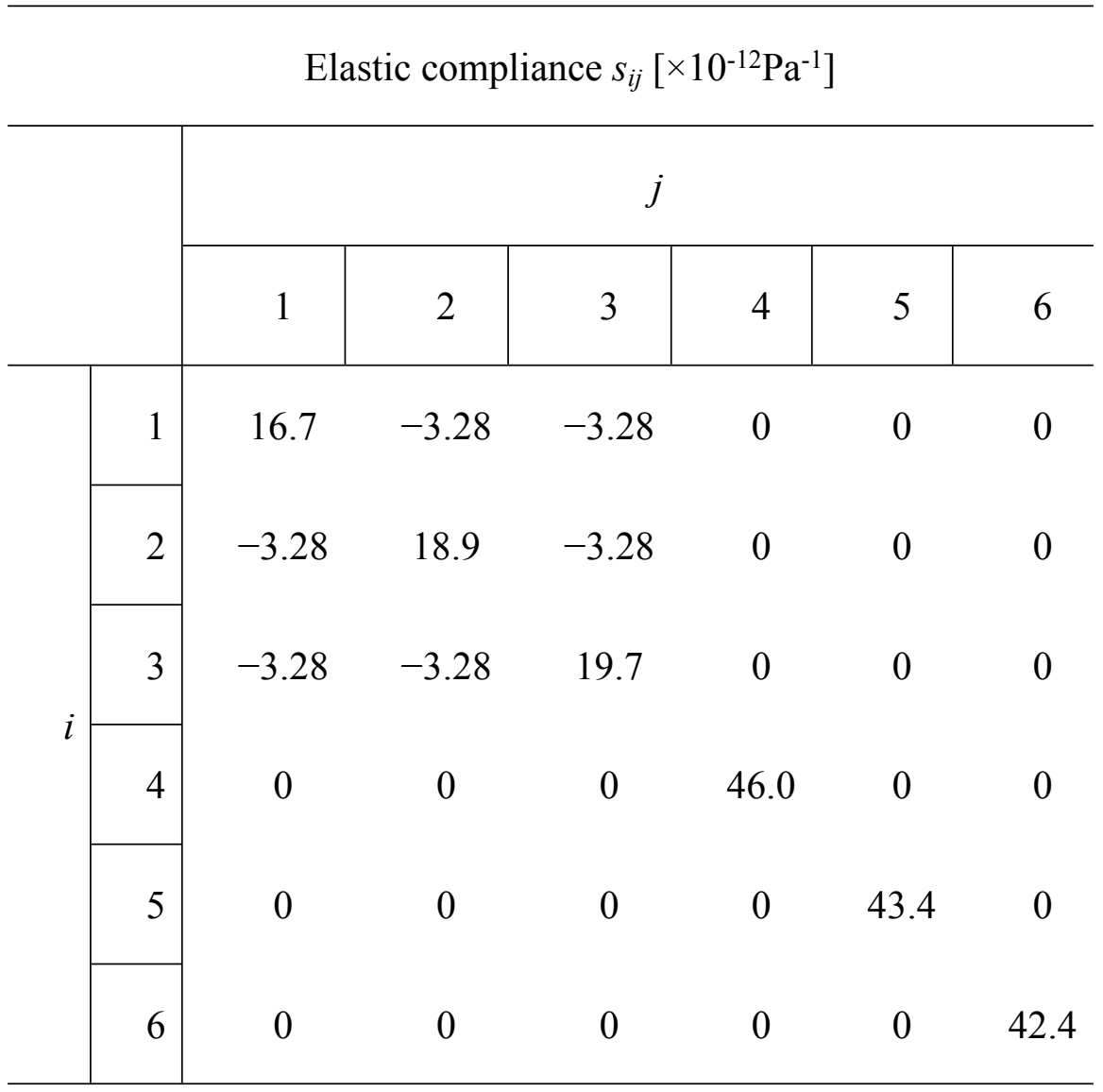

Table 2. Results of subcritical crack growth measurements summarized by the power law.

\begin{tabular}{ccccc}
\hline Condition & $n$ & $\log A$ & $\begin{array}{c}K_{\mathrm{I}}\left(10^{-6}\right) \\
{\left[\mathrm{MN} / \mathrm{m}^{3 / 2}\right]}\end{array}$ & $\begin{array}{c}\mathrm{d} a / \mathrm{d} t(1.6) \\
{[\mathrm{m} / \mathrm{s}]}\end{array}$ \\
\hline distilled water & 51.6 & -16.4 & 1.59 & $1.35 \times 10^{-6}$ \\
$(310 \mathrm{~K}, \mathrm{pH}=6)$ & 29.6 & -11.6 & 1.54 & $2.91 \times 10^{-6}$ \\
\hline $\mathrm{Ca}(\mathrm{OH})_{2}$ & 71.6 & -23.6 & 1.76 & $1.04 \times 10^{-9}$ \\
$(310 \mathrm{~K}, \mathrm{pH}=13)$ & 68.1 & -22.1 & 1.72 & $6.32 \times 10^{-9}$ \\
\hline $\operatorname{air}(322 \mathrm{~K}, 50 \%)$ & 76.7 & -26.9 & 1.87 & $5.70 \times 10^{-12}$ \\
\hline
\end{tabular}


Table 3. Results of subcritical crack growth measurements summarized by the exponential law.

\begin{tabular}{ccccc}
\hline Condition & $\begin{array}{c}b \\
{\left[\mathrm{~m}^{5 / 2} / \mathrm{mol}\right]}\end{array}$ & $\alpha$ & $\begin{array}{c}K_{\mathrm{I}}\left(10^{-6}\right) \\
{\left[\mathrm{MN} / \mathrm{m}^{3 / 2}\right]}\end{array}$ & $\begin{array}{c}\mathrm{d} a / \mathrm{d} t(1.6) \\
{[\mathrm{m} / \mathrm{s}]}\end{array}$ \\
\hline distilled water & 0.056 & -67.1 & 1.60 & $1.16 \times 10^{-6}$ \\
$(310 \mathrm{~K}, \mathrm{pH}=6)$ & 0.050 & -43.6 & 1.54 & $2.63 \times 10^{-6}$ \\
\hline $\mathrm{Ca}(\mathrm{OH})_{2}$ & 0.108 & -86.7 & 1.76 & $1.26 \times 10^{-9}$ \\
$(310 \mathrm{~K}, \mathrm{pH}=13)$ & 0.082 & -82.5 & 1.73 & $6.71 \times 10^{-9}$ \\
\hline air $(322 \mathrm{~K}, 50 \%)$ & 0.112 & -92.4 & 1.88 & $1.01 \times 10^{-11}$ \\
\hline
\end{tabular}




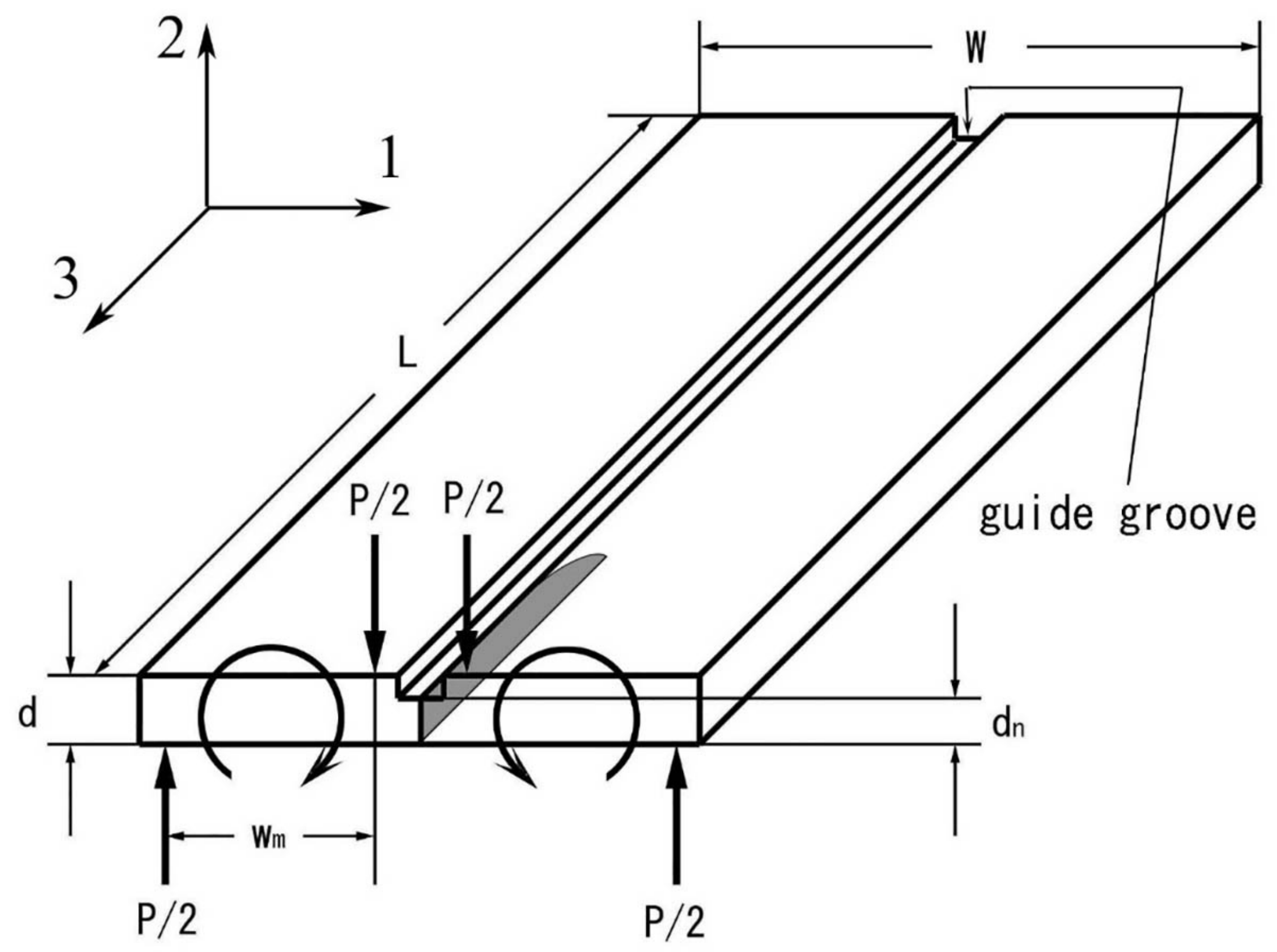



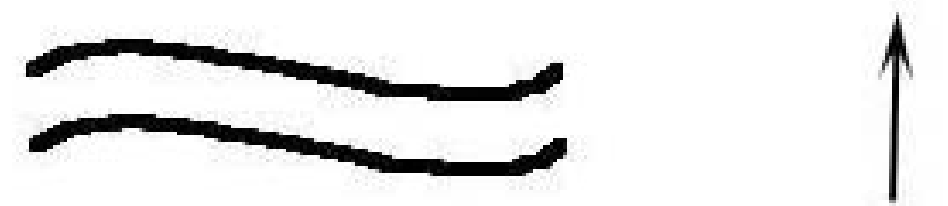

displacement transducer

temperature and humidity

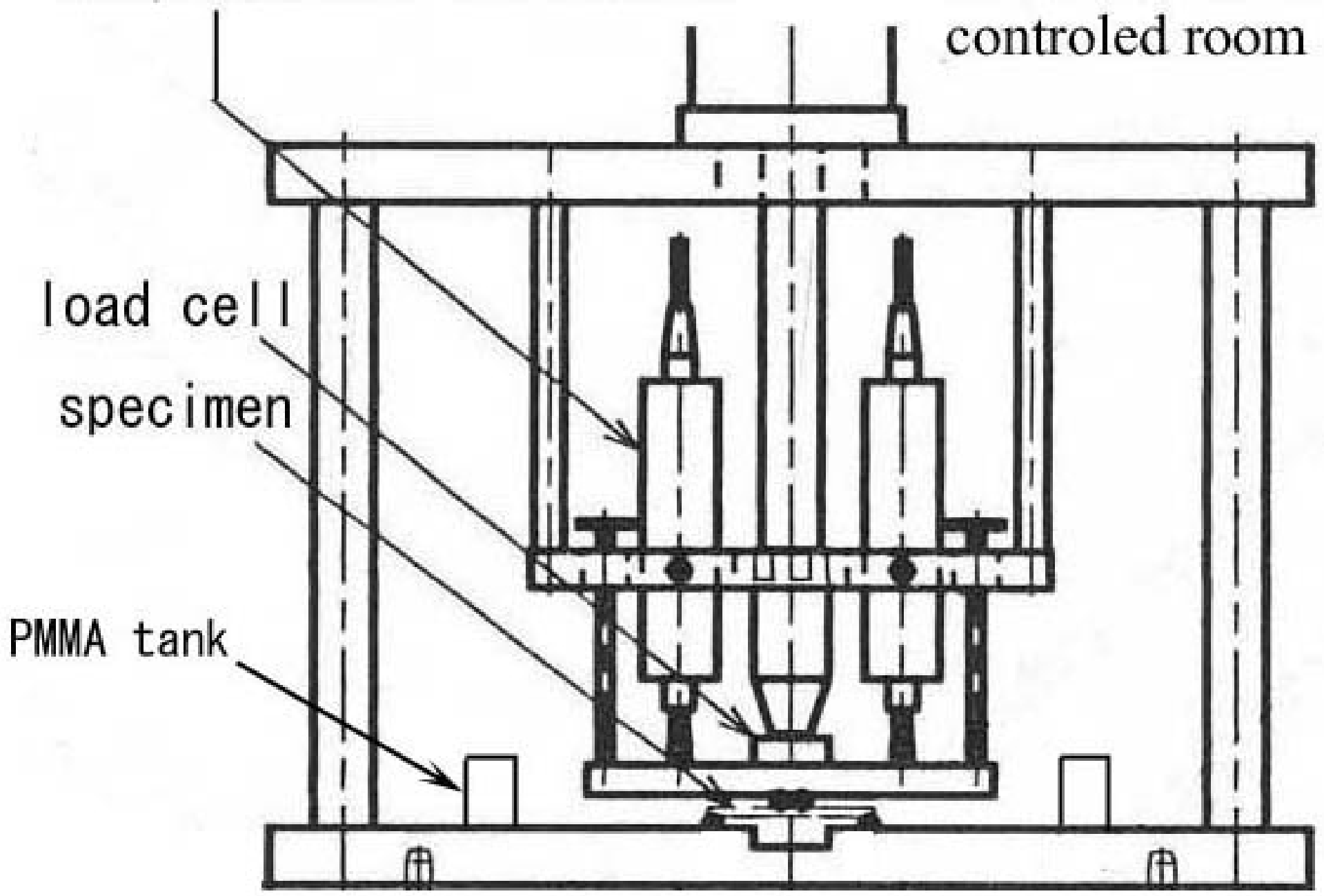




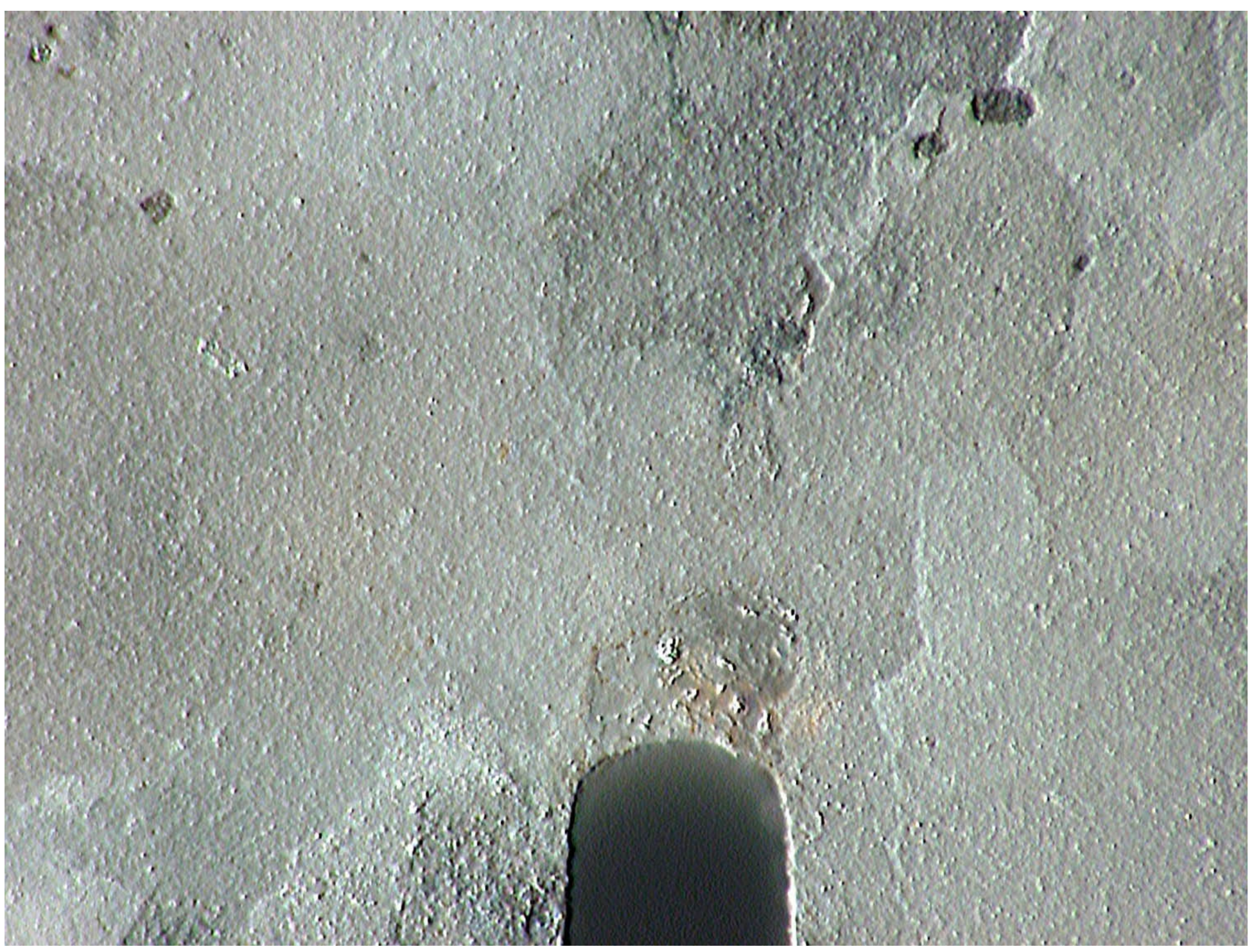




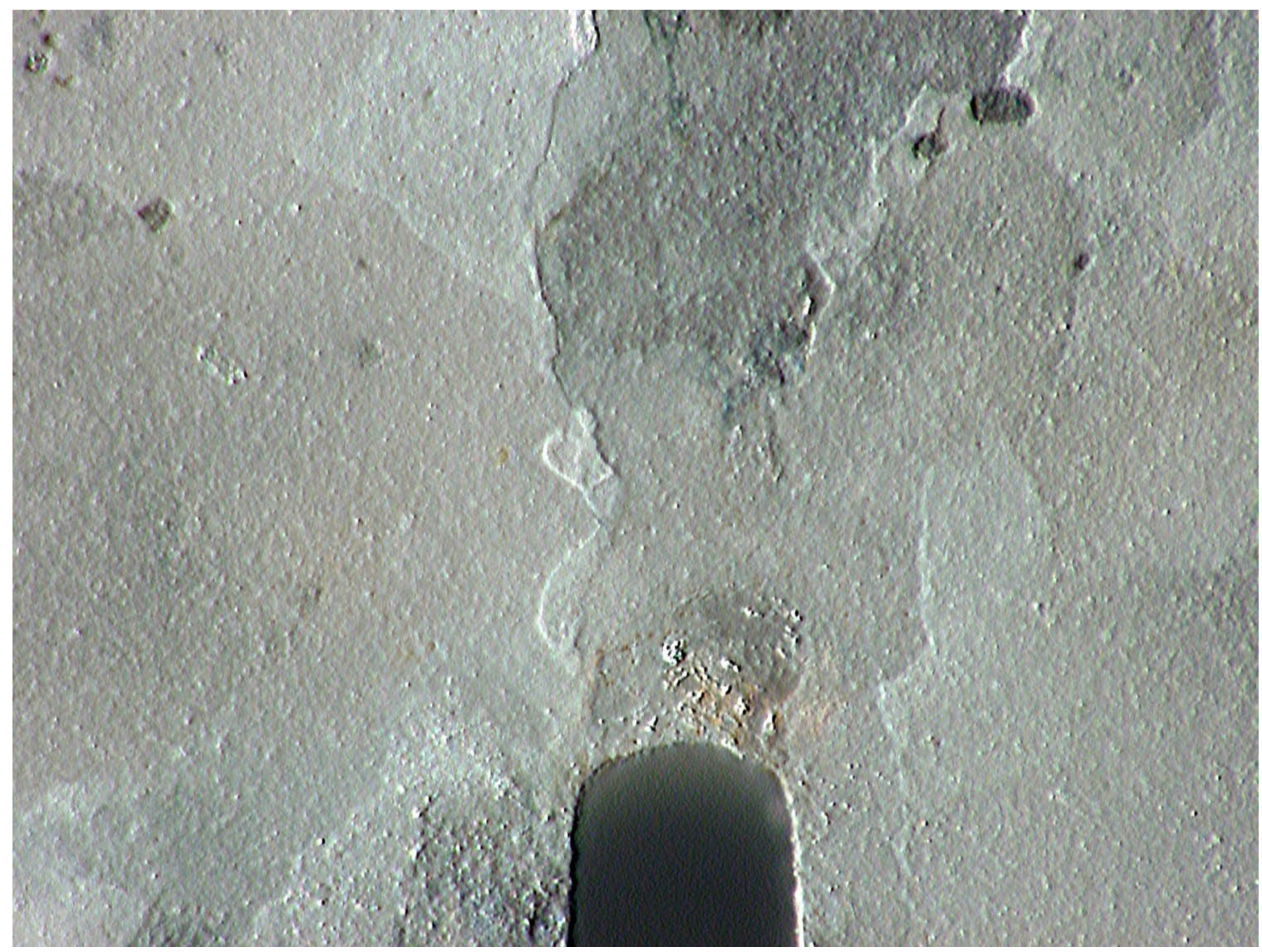




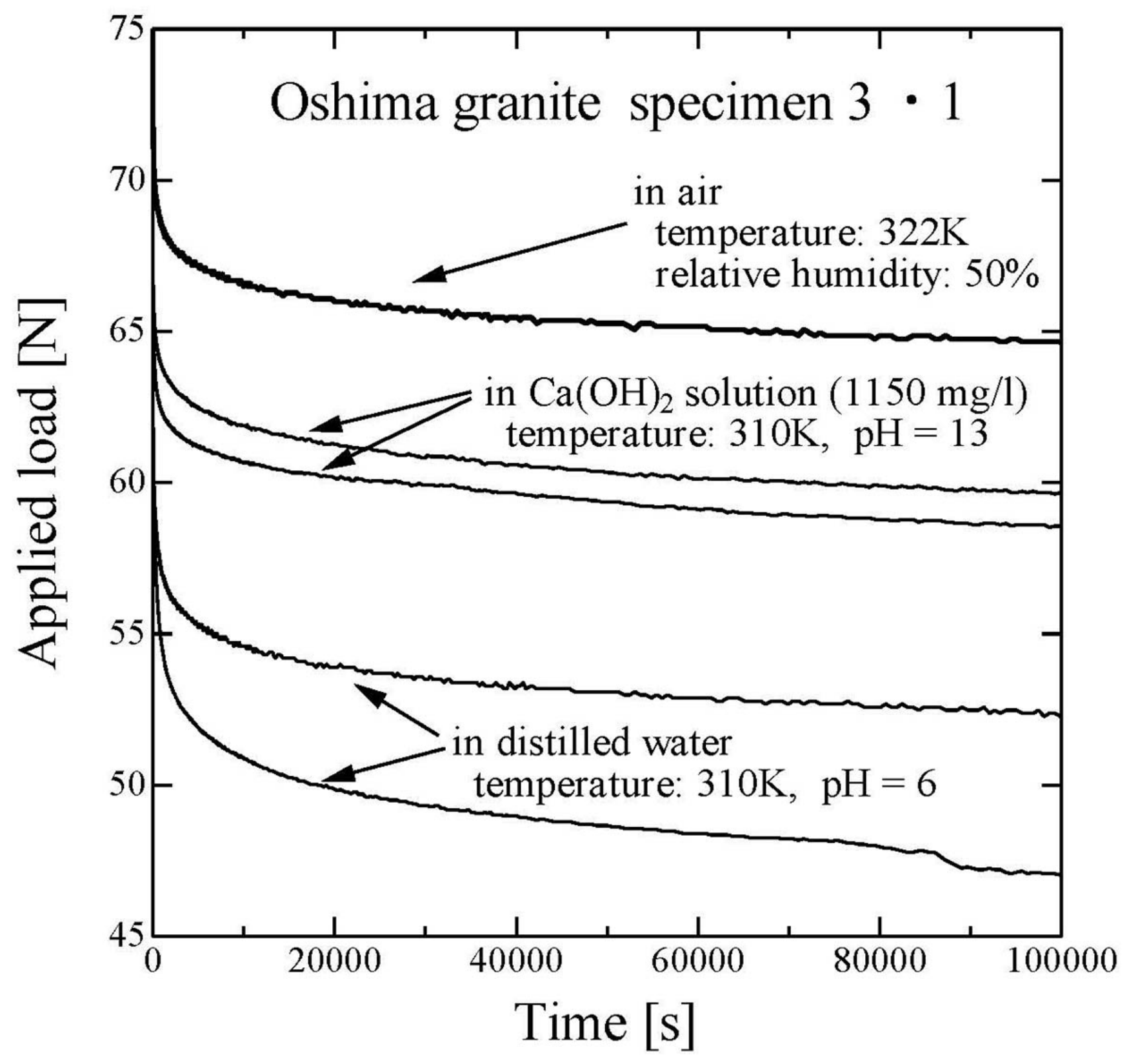




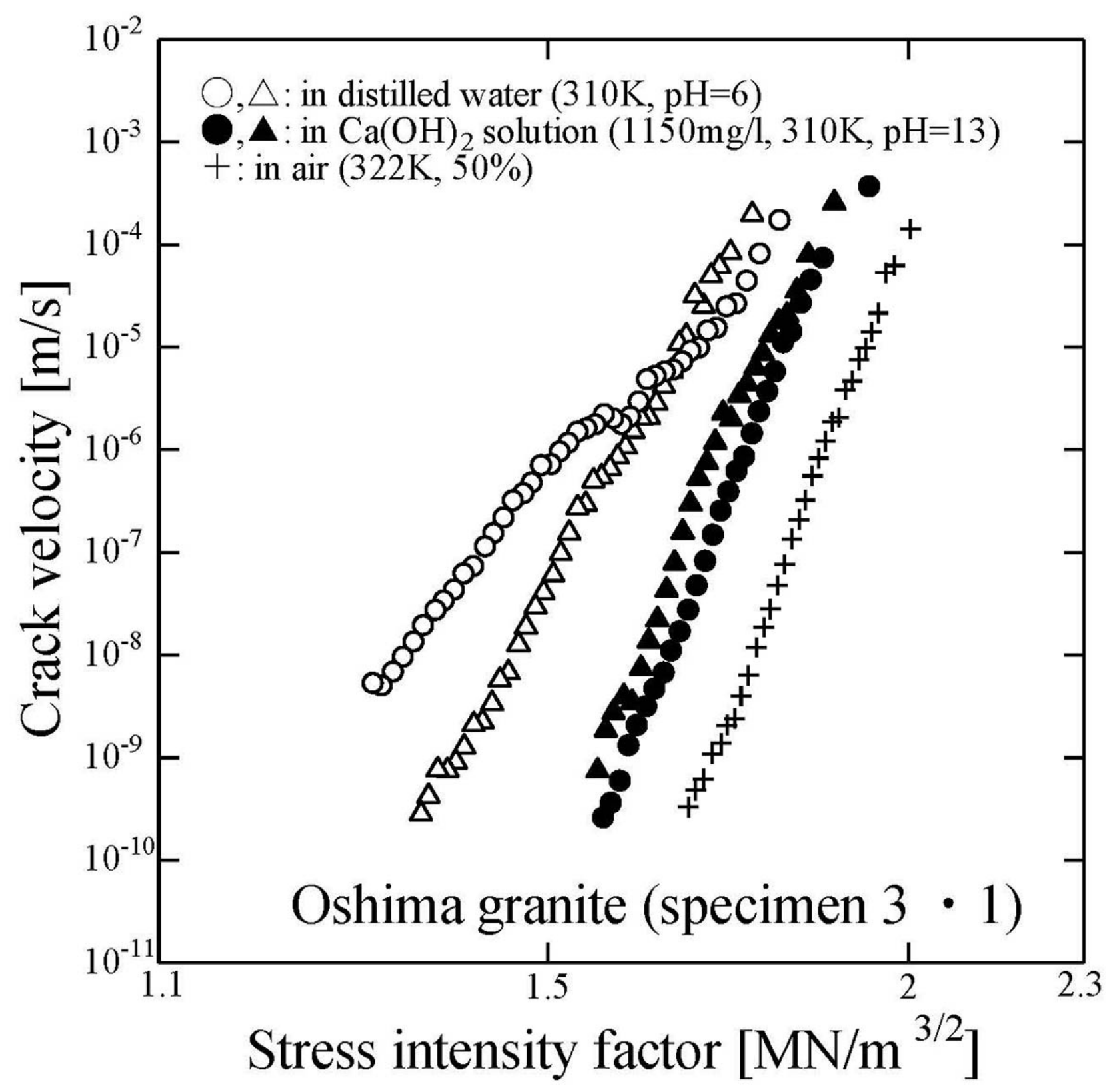




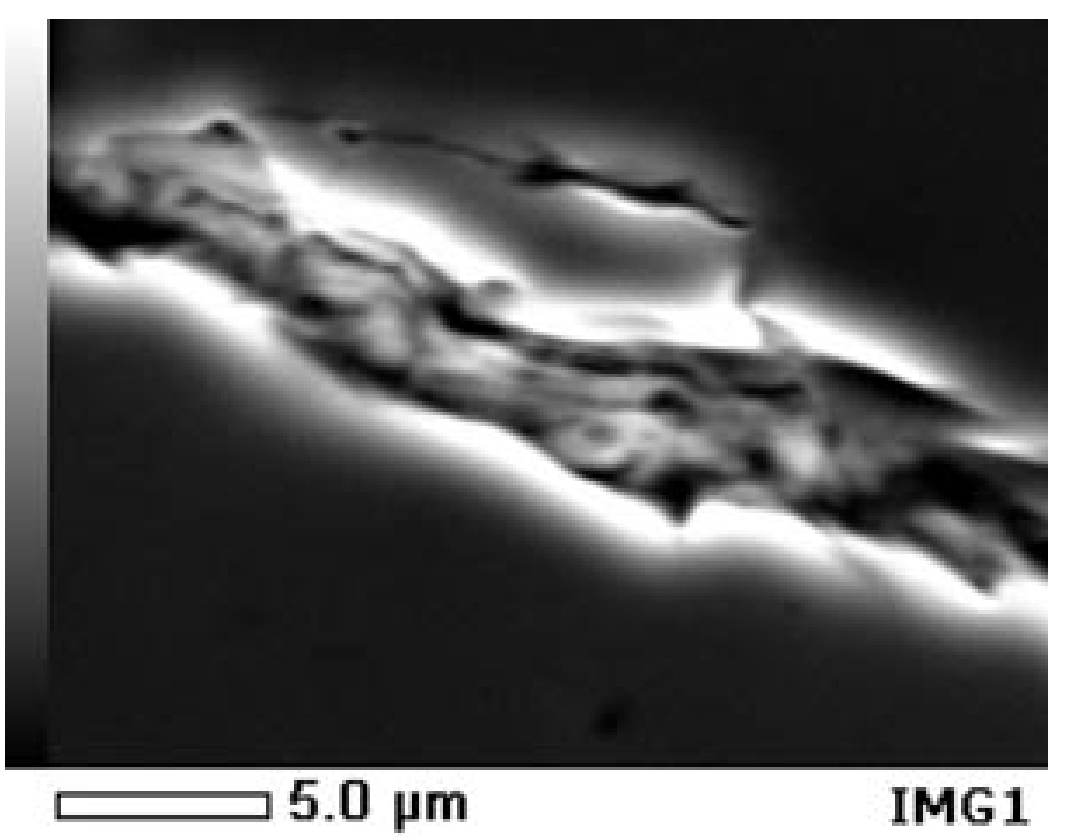




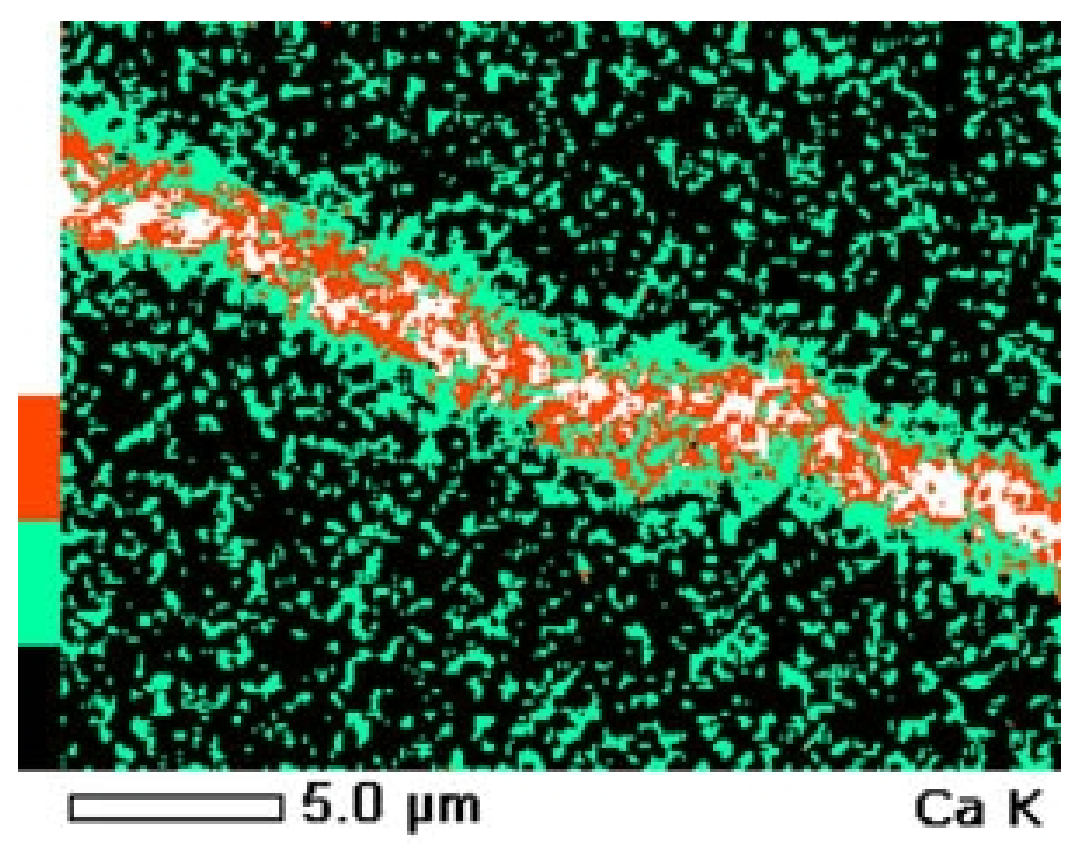




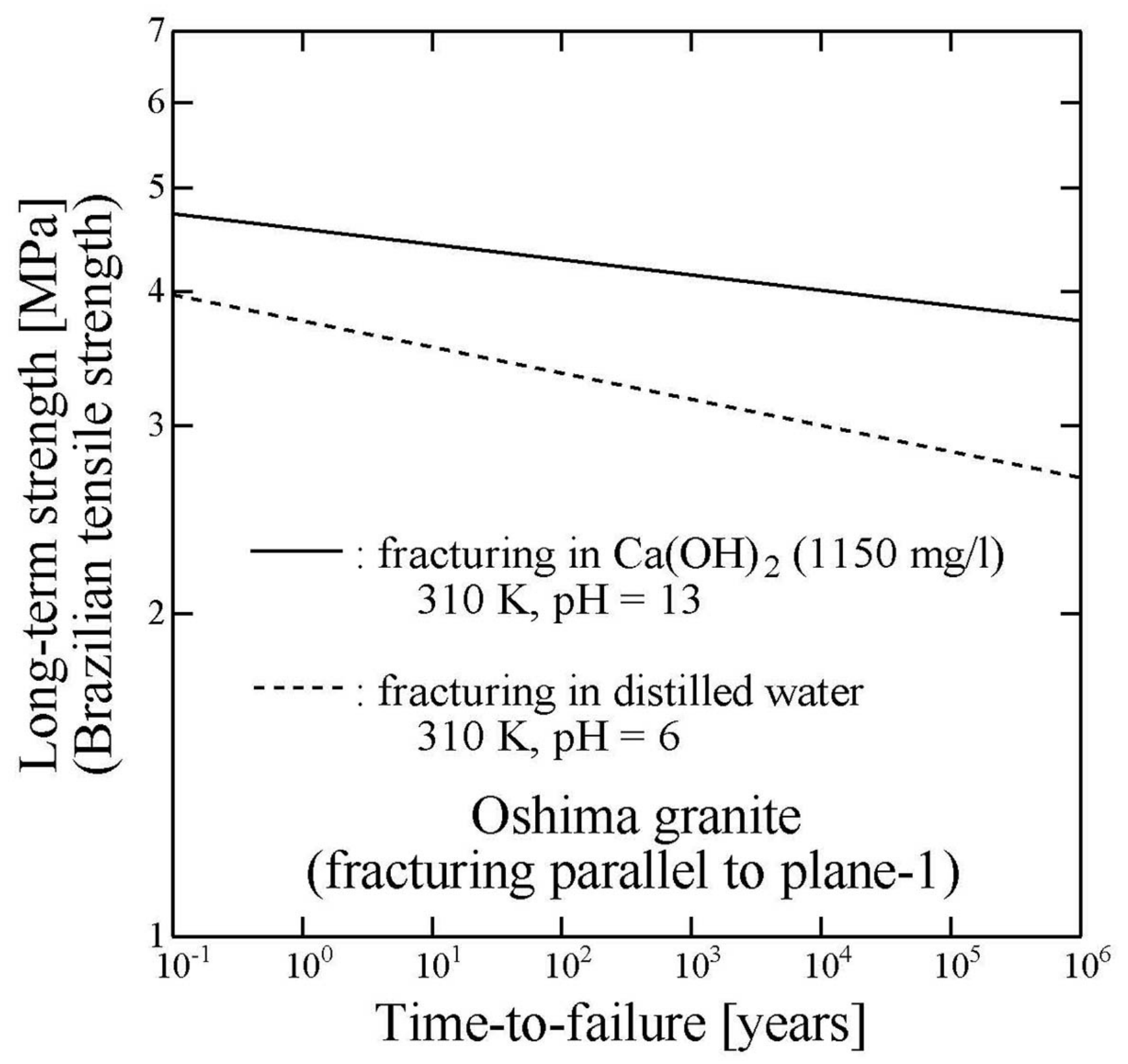




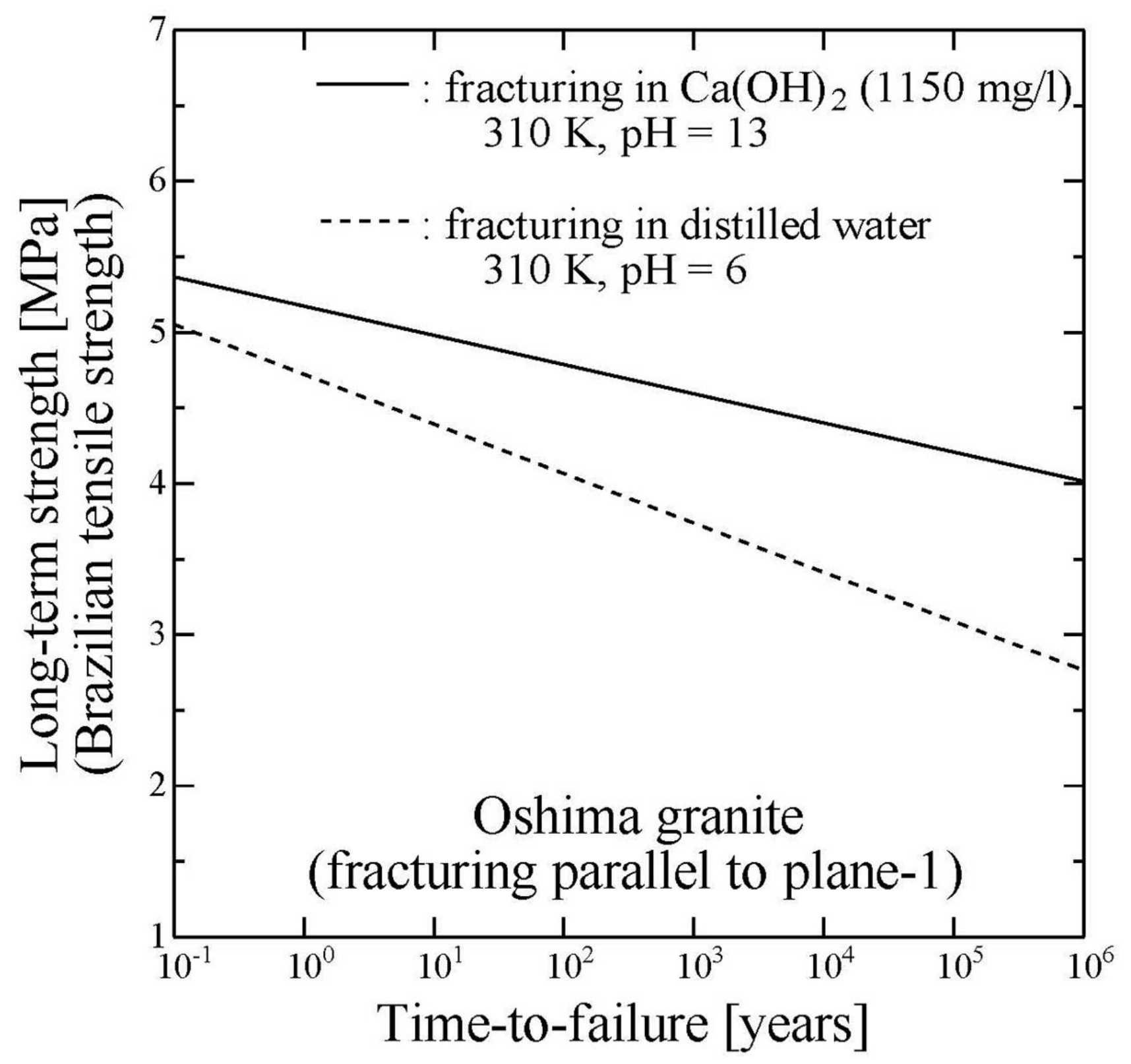

